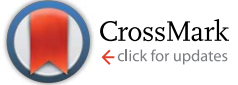

Cite this: RSC Adv., 2016, 6, 71719
Received 14th June 2016 Accepted 21st July 2016

DOI: 10.1039/c6ra15442e

www.rsc.org/advances

\section{Evaluation of the thermochemical properties of Ho-Cd intermetallic compounds using electrochemical techniques}

\author{
Y. Castrillejo,* F. Oduber and E. Barrado
}

The electrochemical formation of $\mathrm{HoCd}_{6}, \mathrm{HoCd}_{45 / 11}, \mathrm{HoCd}_{3}, \mathrm{HoCd}_{2}$ and $\mathrm{HoCd}$, on a $\mathrm{Cd}$ coated tungsten electrode in the eutectic $\mathrm{LiCl}-\mathrm{KCl}$ has been evaluated in a qualitative and quantitative manner using electrochemical techniques (i.e. cyclic voltammetry, anodic stripping voltammetry and open circuit chronopotentiometry) over the temperature range of 673-823 K. The formation energy of each intermetallic compound, as well as the global formation constants were calculated for the first time. The activities and relative partial molar Gibbs energies of $\mathrm{Ho}$ and $\mathrm{Cd}$ were also obtained for $\mathrm{HoCd}_{6}, \mathrm{HoCd}_{45 /}$ 11, $\mathrm{HoCd}_{3}, \mathrm{HoCd}_{2}$ and $\mathrm{HoCd}$. At the $\mathrm{Cd}$ distillation temperature, the molar Gibbs free energy of the intermetallic compounds achieves the minimum value for $\mathrm{HoCd}_{2}$ and $\mathrm{HoCd}$, suggesting that the dissolution of $\mathrm{U}$ or Pu from the $\mathrm{U}-\mathrm{Pu}-\mathrm{Ho}-\mathrm{Cd}$ alloy into $\mathrm{HoCd}_{2}$ and $\mathrm{HoCd}$ should be considered.

\section{Introduction}

Pyro reprocessing fuel cycle technology appears as an encouraging candidate to carry out an advanced fuel cycle with reduced loads of long life radioactive waste and no proliferation risk. In a closed fuel cycle scenario, the radiotoxicity of the spent nuclear fuel can be reduced separating the Long-Lived Fission Products (LLFP) and Minor Actinides (MAs), which are burned and converted into short-lived isotopes. This strategy, known as partitioning and transmutation (P\&T), could be carried out in dedicated accelerator driven systems or integrated in the advance fuel cycle of a fast reactor system. ${ }^{\mathbf{1}}$

In pyrochemical reprocessing, the separation takes place in a molten salt media (i.e. chlorides or fluorides) due to their advantageous properties, mainly their high radiation stability and thermal resistance, which allows the processing of spent fuels with short cooling times, and not being neutron moderators, a large amount of fissile material can be handled. ${ }^{2}$ In pyrochemical reprocessing, the proposed separation strategies are: (i) electrodeposition on inert (generally $\mathrm{W}$ or $\mathrm{Mo}$ ) and reactive (e.g. $\mathrm{Cd}, \mathrm{Bi}, \mathrm{Al}$ ) cathodes, and (ii) molten salt reductive extraction using a liquid metal. Special attention must be given to lanthanides, Lns, the most awkward FPs to be separated from the Ans, since their large capture cross sections would spoil the neutron economy of the reactor core in the transmutation stage. ${ }^{3}$ It merits to be mentioned, that during the separation stage the Lns accumulate in the molten salt media modifying its characteristics and contaminating

Dpto de Química Analitica, Facultad de Ciencias, Universidad de Valladolid, Campus Miguel Delibes. Paseo de Belén 7, 47011 Valladolid, Spain.E-mail: ycastril@qa.uva. es; ebarrado@qa.uva.es the final product. Therefore, in order to ensure a longer lifetime of the media, it is required to remove the Lns from the salts after the selective extraction of Ans, ${ }^{4}$ activities in which our team has been engaged since 2000 .

Cd is assumed to be a typical liquid metal to be used in pyrochemical reprocessing, since Cd has a low melting point (594 K) and the activities of Ans and Lns in the metallic phase are very small. ${ }^{5}$ In this way, the electrochemical behaviour of some Ans and Lns has been examined using a liquid cadmium cathode..$^{5-19}$ Nevertheless, there are still many of them that need to be explored in terms of electrochemical and thermodynamic properties. This is the case of holmium, a heavy lanthanide object of the present paper, in which its electrode reactions at a Cd coated W electrode, were investigated, with the aim to calculate the Gibbs free energies of formation of the different Ho-Cd intermetallic compounds, as well as the activities and relative partial molar Gibbs energies of Ho and Cd, by means of electrochemical techniques. The paper describes the methods used and the obtained results.

\section{Experimental}

Chemical storage, electrolytic bath and sample preparation were handled in a MBraun glove box in purified Ar atmosphere. The electrolytic bath, $80 \mathrm{~g}$ of the eutectic LiCl-KCl, was introduced in a high purity $100 \mathrm{~cm}^{3}$ alumina crucible placed in a cylindrical quartz cell and then fused under vacuum and purified with $\mathrm{HCl}(\mathrm{g})$ following the methodology described elsewhere. ${ }^{\mathbf{1 4 , 1 7}}$

Holmium and cadmium ions were introduced into the bath in the form of anhydrous $\mathrm{HoCl}_{3}$ and $\mathrm{CdCl}_{2}$ (Sigma Aldrich 99.99\%). The experiments were performed under a dry $\mathrm{Ar}$ 
atmosphere, and the temperatures were controlled with a nickel-chromium thermocouple.

Different working electrodes have been used: (i) a tungsten wire of $1.0 \mathrm{~mm}$ diameter, (ii) a liquid $\mathrm{Cd}$ bulk electrode, prepared by placing some granules of Cd (99.999\%; Sigma Aldrich) in a J shaped Pyrex tube, establishing the contact by means of a tungsten wire immersed in the Cd phase through the Pyrex tube, and (iii) a tungsten wire of $1.0 \mathrm{~mm}$ diameter (Sigma Aldrich 99.99\%) coated with $\mathrm{Cd}(0)$. As counter electrodes, a glassy carbon rod (Sofagel) of $3 \mathrm{~mm}$ diameter and a 1.5 mm diameter tungsten wire (Alfa Aesar 99.95\%) have been used. All the potentials were referred to the equilibrium potential adopted by a silver wire dipped into an $\mathrm{AgCl}$ solution $(0.75 \mathrm{~mol}$ $\left.\mathrm{kg}^{-1}\right)$ in the LiCl-KCl mixture, contained in a Pyrex tube.

The electrochemical measurements were performed with a potentiostat/galvanostat, either a PAR EG\&G Model 273A controlled by the EG\&G M270 software or an Autolab PGSTAT $320 \mathrm{~N}$ controlled by the NOVA 1.10 research software.

\section{Results and discussion}

\section{Electrode reactions of $\mathrm{Ho}(\mathrm{III}) / \mathrm{Ho}$ system in the reactive $\mathrm{Cd}$ pool electrode}

Fig. 1 displays the electrochemical spectra obtained with a solution of dissolved $\mathrm{HoCl}_{3}$ in the eutectic bath, probably as the entity $\mathrm{HoCl}_{6}{ }^{3-}$ and hereafter $\mathrm{Ho}(\mathrm{III})$. Curve (1) has been registered at the liquid $\mathrm{Cd}$ pool electrode, whereas curve (2) at the $\mathrm{W}$ one, in order to compare with the liquid substrate because no alloys exist for the W-Ho binary systems. Another electrochemical spectra, the red dotted curve (3), has also been recorded at the $\mathrm{Cd}$ pool electrode in the absence of $\mathrm{Ho}(\mathrm{III})$, being the cathodic limit attributed to the Li deposition in $\mathrm{Cd},{ }^{5}$ and the anodic one to the anodic dissolution of the own electrode.

If the substrate is an inert material, as we have reported previously, ${ }^{20}$ the reaction proceeds as a simple deposition/ dissolution mechanism:

$$
\mathrm{Ho}(\mathrm{III})+3 \mathrm{e} \rightleftharpoons \mathrm{Ho}(0)
$$

whereas, at the Cd pool the mechanism seems to be different. The voltammogram consist in a cathodic wave, $\mathrm{A}^{\mathrm{c}}$, related to

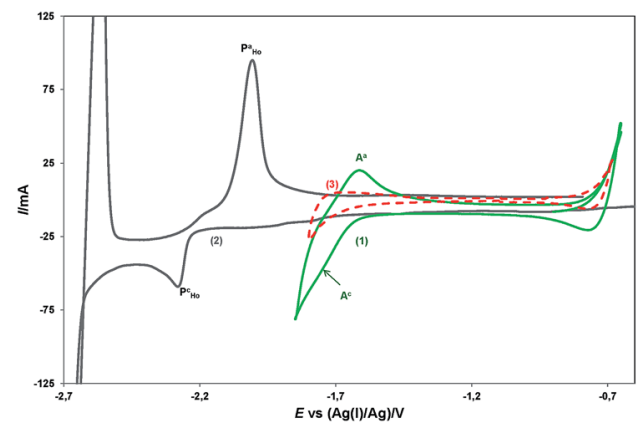

Fig. 1 CVs registered with a $\mathrm{HoCl}_{3}$ solution $\left(C_{0}=1.17 \times 10^{-4} \mathrm{~mol}\right.$ $\mathrm{cm}^{-3}$ ) at a Cd pool, curve (1), and a W electrode, curve (2). Curve (3) shows the $\mathrm{CV}$ obtained at the $\mathrm{Cd}$ pool electrode in absence of $\mathrm{HoCl}_{3}$. Scan rate: $100 \mathrm{mV} \mathrm{s}^{-1}$; temperature $698 \mathrm{~K}$. a best defined anodic one, $\mathrm{A}^{\mathrm{a}}$, suggesting by their shape that they are due to the deposition of $\mathrm{Ho}$ in $\mathrm{Cd}, \mathrm{Ho}_{(\mathrm{Cd})}$, and the oxidation of the Ho dissolved in $\mathrm{Cd}$, respectively. A similar behavior to those reported for other Lns and Ans in liquid cathodes. ${ }^{5,11,17,22-24}$

$$
\mathrm{Ho}(\mathrm{III})+\mathrm{Cd}+3 \mathrm{e} \rightleftharpoons \mathrm{Ho}_{(\mathrm{Cd})}
$$

From a thermodynamic point of view, the potential shift of the electrochemical system in the anodic direction versus the $\mathrm{W}$ electrode, is caused by the decrease in the activity of Ho, which is dissolved in the Cd phase, as described in eqn (3)

$$
E_{\text {eq }}=E_{\mathrm{Ho}(\mathrm{III}) / \mathrm{Ho}}^{0}+\frac{R T}{3 F} \ln \frac{a_{\mathrm{Ho}(\mathrm{III}) \text { in solution }}}{a_{\mathrm{Ho}(\mathrm{Cd})}}
$$

On the other hand, as in the case of the $\mathrm{Hg}$ electrode in aqueous solutions, ${ }^{22}$ the reaction scheme can also be viewed, as an electrochemical-chemical, EC, process, described by eqn (1) and (4)

$$
\mathrm{Ho}+\mathrm{Cd} \rightleftharpoons \mathrm{Ho}(\mathrm{Cd})
$$

The chemical step (4) can be considered as an equilibrium step, being the product of the charge transfer (1) stabilized by this step, and hence the $E_{1 / 2}$ is shifted in the positive direction.

It merits to be mentioned that if the amount of electrodeposited Ho surpasses its solubility in $\mathrm{Cd}$, the electrode homogeneity is lost, appearing separated solid phases (i.e. intermetallic compounds), a phenomenon that can be observed in Fig. 2. When the inversion potential achieves cathodic values greatest than $-1.85 \mathrm{~V}$, in addition to the cathodic wave $\mathrm{A}^{\mathrm{c}}$, an important cathodic current is noticeable, appearing in the reverse scan a new signal, labelled $\mathrm{B}^{\mathrm{a}}$, at around $-1.72 \mathrm{~V}$, with the shape of a dissolution peak. Therefore, part of the cathodic current would be caused by the deposition of an intermetallic compound, probably $\mathrm{HoCd}_{6}$, which according to the reported data $^{21}$ is the intermetallic with the richer content in Cd, being the peak $\mathrm{B}^{\mathrm{a}}$ produced by its reoxidation. Hence, the transformations should be as follows:

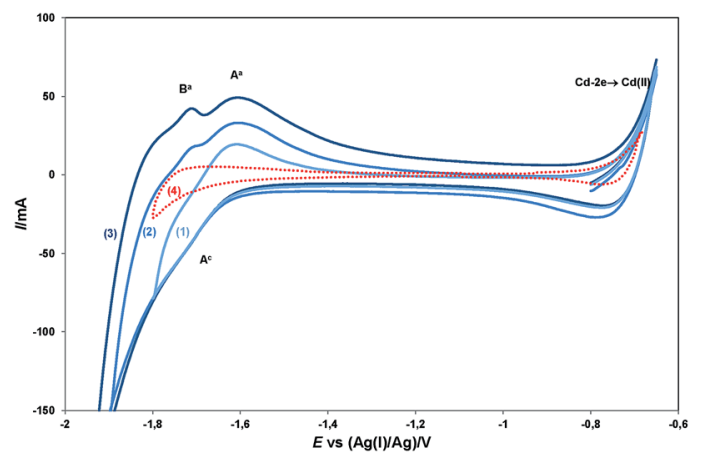

Fig. 2 CVs obtained with a Ho(III) solution $\left(C_{0}=1.17 \times 10^{-4} \mathrm{~mol} \mathrm{~cm}^{-3}\right)$ at a $\mathrm{Cd}$ pool electrode (scan rate: $100 \mathrm{mV} \mathrm{s}^{-1}, \mathrm{~T}: 698 \mathrm{~K}$ ) at different inversion potentials, curves (1-3). Curve (4) cyclic voltammogram registered with the $\mathrm{Cd}$ pool electrode in absence of $\mathrm{HoCl}_{3}$. 
Peak $A^{\mathrm{a}}$ :

$$
\mathrm{Ho}_{(\mathrm{Cd})}-3 \mathrm{e} \rightarrow \mathrm{Ho}(\mathrm{III})+\mathrm{Cd}
$$

Peak $\mathrm{B}^{\mathrm{a}}$ :

$$
\mathrm{HoCd}_{6}-3 \mathrm{e} \rightarrow \mathrm{Ho}(\mathrm{III})+6 \mathrm{Cd}
$$

\section{Electrode reaction of $\mathrm{Ho}(\mathrm{III})$ at cadmium film electrodes}

According to the literature ${ }^{21}$ holmium can form five intermetallic compounds with Cd (i.e. $\operatorname{HoCd}_{6}, \mathrm{Ho}_{11} \mathrm{Cd}_{45}, \mathrm{HoCd}_{3}, \mathrm{HoCd}_{2}$ and HoCd).

With the aim to obtain thermodynamic information concerning their formation, the electrochemical behaviour of $\mathrm{Ho}(\mathrm{III})$ on a tungsten electrode coated with a thin film of $\mathrm{Cd}$, CdFE, has been studied by using electrochemical techniques. Due to its small volume, the CdFE, purposefully made to be thin, has been chosen instead of the Cd pool. Since the thickness of the film is smaller than the diffusion layer ones, the semi-infinite diffusion model is not valid in the CdFE, and distinct non-homogeneous phases will be formed during deposition. $^{22}$

\section{Detection of intermetallic compounds}

Fig. 3 shows the electrochemical spectrum (blue line) obtained with a Cd(II) solution on a W electrode at $698 \mathrm{~K}$, which has been divided in two consecutive zones. In zone (I) a group of signals (peaks $\mathrm{P}_{\mathrm{Cd}}^{\mathrm{c}} / \mathrm{P}_{\mathrm{Cd}}^{\mathrm{a}}$ ) is observed, which corresponds to the $\mathrm{Cd}(\mathrm{II})$ reduction to $\mathrm{Cd}(0)$ following a single-step process exchanging 2 electrons. ${ }^{17,25}$ In zone II, and before the massive reduction of lithium, 3 groups of signals $\mathrm{I}_{\mathrm{c}} / \mathrm{I}_{\mathrm{a}}, \mathrm{II}_{\mathrm{c}} / \mathrm{II}_{\mathrm{a}}$, and $\mathrm{III}_{\mathrm{c}} / \mathrm{III}_{\mathrm{a}}$ are evident, that can be attributed to the formation of $\mathrm{Li}-\mathrm{Cd}$ and/or $\mathrm{K}-\mathrm{Cd}$ alloys by underpotential deposition (UPD) of the alkaline on the liquid cadmium already deposited and coating the tungsten electrode. In order to facilitate a comparison, in Fig. 3 it has also been represented the spectrum recorded on a tidy $\mathrm{W}$ electrode with a $\mathrm{Ho}$ (III) solution at the same temperature (red line)

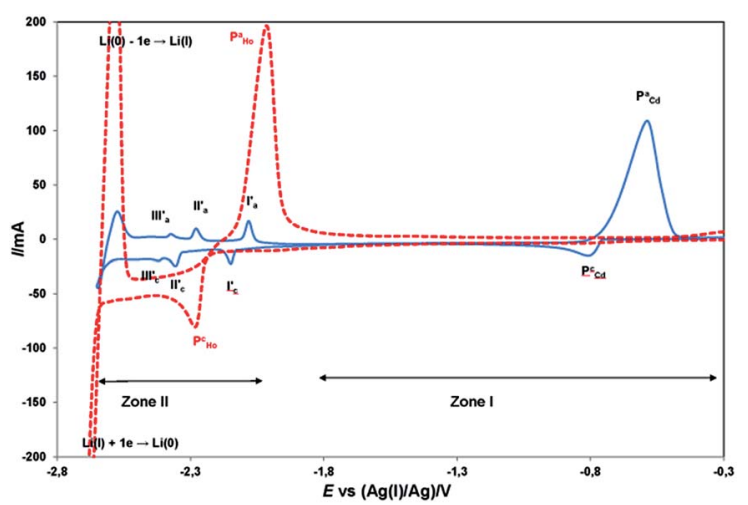

Fig. 3 CVs registered at $200 \mathrm{mV} \mathrm{s}^{-1}$ and $673 \mathrm{~K}$ on a W electrode with a $C d(I)$ solution $\left(C_{0}=7.85 \times 10^{-5} \mathrm{~mol} \mathrm{~cm}^{-3}\right.$ ) (continuous blue line). Cyclic voltammograms for the reduction of a $\mathrm{HoCl}_{3}$ solution in the eutectic $\mathrm{LiCl}-\mathrm{KCl}\left(C_{0}=1.17 \times 10^{-4} \mathrm{~mol} \mathrm{~cm}^{-3}\right)$ (dotted red line).

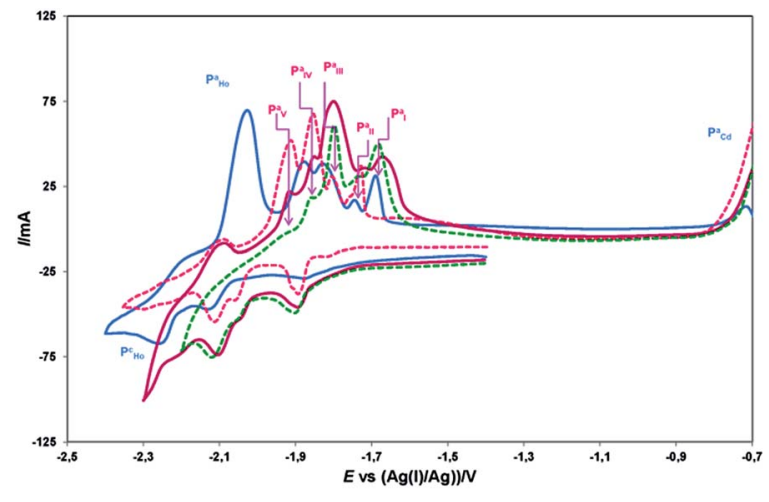

Fig. $4 \mathrm{CVs}$ registered at different inversion potentials at $100 \mathrm{mV} \mathrm{s}^{-1}$ and $723 \mathrm{~K}$ with a solution containing $\mathrm{Ho}(\mathrm{III}) 1.14 \times 10^{-4} \mathrm{~mol} \mathrm{~cm}^{-3}$ on a CdFE electrogenerated "in situ" at $-1.4 \mathrm{~V}\left(\left[\mathrm{CdCl}_{2}\right]=1.16 \times 10^{-5} \mathrm{~mol}\right.$ $\mathrm{cm}^{-3}$ ).

exhibiting the aforementioned electrochemical signals $\left(\mathrm{P}_{\mathrm{Ho}}^{\mathrm{c}} /\right.$ $\mathrm{P}_{\mathrm{Ho}}^{\mathrm{a}}$ ). Taken into account all this information, the formation of a Cd film can be carried out at the surface of a tidy $\mathrm{W}$ electrode, "ex situ" (i.e. in a $\mathrm{LiCl}-\mathrm{KCl}$ bath containing $\mathrm{CdCl}_{2}$ ) or "in situ" (i.e. in a LiCl- $\mathrm{KCl}$ cell containing both $\mathrm{Ho}(\mathrm{III})$ and $\mathrm{Cd}(\mathrm{II})$ ), by potentiostatic electrolysis at more cathodic potentials than $-0.82 \mathrm{~V}($ e.g. $-1.4 \mathrm{~V})$ for a little period.

Fig. 4 shows typical examples of the cyclic voltammograms registered with a CdFE electrogenerated "in situ" at $698 \mathrm{~K}$. A series of new redox couples can be observed between the electrochemical signals $\mathrm{P}_{\mathrm{Ho}}^{\mathrm{c}} / \mathrm{P}_{\mathrm{Ho}}^{\mathrm{a}}$ and $\mathrm{P}_{\mathrm{Cd}}^{\mathrm{a}}$, which are attributed to the formation/dissolution of different Ho-Cd intermetallic compounds. The anodic peaks, $\mathrm{P}_{\mathrm{V}}^{\mathrm{a}}, \mathrm{P}_{\mathrm{IV}}^{\mathrm{a}}, \mathrm{P}_{\mathrm{III}}^{\mathrm{a}}, \mathrm{P}_{\mathrm{II}}^{\mathrm{a}}$, and $\mathrm{P}_{\mathrm{I}}^{\mathrm{a}}$, better defined than their corresponding cathodic ones, are due to the dissolution of $\mathrm{Ho}$ as $\mathrm{Ho}(\mathrm{III})$ into the LiCl-KCl, with the corresponding transformation of one intermetallic compound into another one with less Ho amount.

Anodic striping voltammetry, ASV, is a simple and easy "in situ" method of redissolution that has been found to be particularly useful for phase identification in metallic alloys.

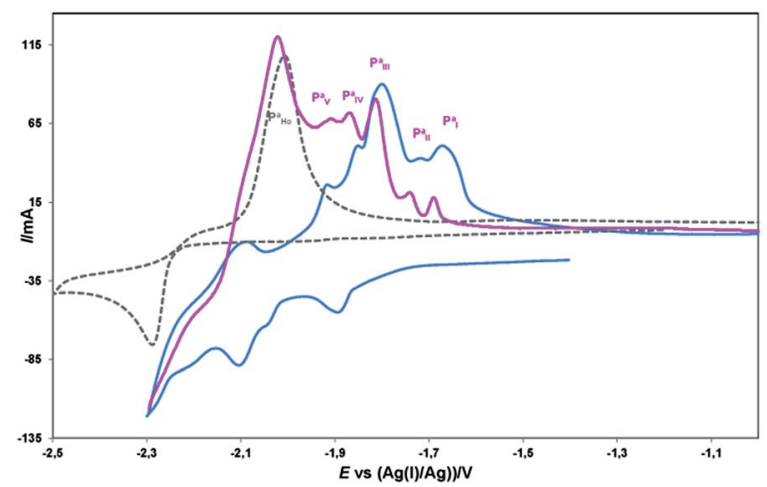

Fig. 5 Pink line, ASV obtained at $723 \mathrm{~K}$ with a solution of $\mathrm{Ho}(\mathrm{III}) 1.14 \times$ $10^{-4} \mathrm{~mol} \mathrm{~cm}^{-3}$ on a $\mathrm{Cd}$ coated $\mathrm{W}$ electrode, $\left(E_{\mathrm{d}}=-2.3 \mathrm{~V}, t_{\mathrm{d}}=20 \mathrm{~s}\right.$, scan rate $50 \mathrm{mV} \mathrm{s}^{-1}$ ). Blue line, $\mathrm{CV}$ registered with the same solution at the same temperature on a $\mathrm{Cd}$ coated $\mathrm{W}$ electrode scan rate $100 \mathrm{mV}$ $\mathrm{s}^{-1}$. Grey line, CV obtained on a tidy W electrode. 


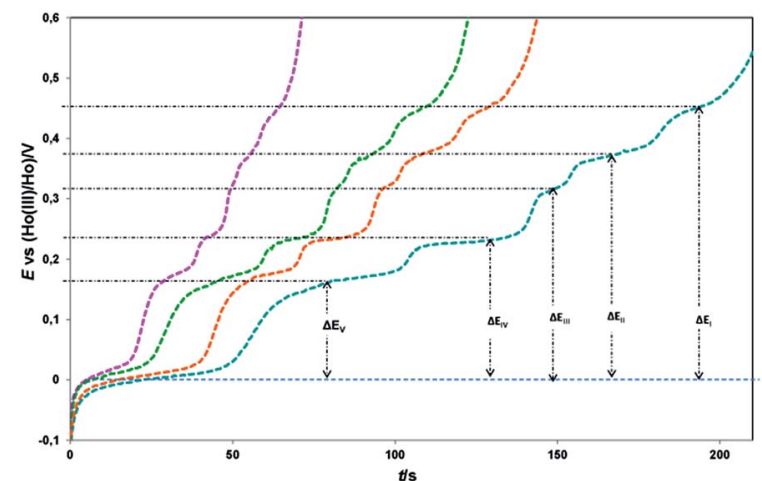

Fig. 6 Examples of the open circuit transient curves (OCP) for a W based $\mathrm{Cd}$ film electrode, electrogenerated in situ, after depositing $\mathrm{Ho}$ at $-2.25 \mathrm{~V}$ vs. $(\mathrm{Ag}(\mathrm{I}) / \mathrm{Ag})$ for $20(-), 40(-), 60(-)$ and $80 \mathrm{~s}(-)$ at $723 \mathrm{~K}$.
The technique is very sensitive to the interaction between the components, revealing the presence of different phases. ${ }^{26}$ Dissolution of Ho-Cd intermetallic compounds displays an anodic current pattern with a series of dissolution peaks, reflecting successive dissolution of $\mathrm{Ho}$, the less noble component, from each phase separately. This behaviour can be explained by the energies of formation of the intermetallic compounds, rendering different dissolution potentials.

To obtain qualitative information, samples of thin layers of Ho-Cd alloys were prepared as follows: The CdFE was electrogenerated by cathodic deposition at $-1.4 \mathrm{~V}$, thereafter the potential was maintained at a value corresponding to the deposition of Ho at a tidy W electrode for synthetizing HoCd, the intermetallic compound with the richer content in Ho. Following the deposition time, the potential was scanned anodically. Fig. 5 illustrates an example of the stripping voltammograms. The ASV (pink line) shows, in addition to the

Table 1 Thermodynamic properties of Ho for Ho-Cd intermetallic compounds in two-phase coexisting states at various temperatures

\begin{tabular}{lllll}
\hline$T(\mathrm{~K})$ & Number of data & $\Delta E_{\mathrm{Ho}(\mathrm{III} / \mathrm{Ho}}(\mathrm{V})$ & $\Delta \tilde{G}_{\mathrm{Ho}}\left(\mathrm{kJ}(\mathrm{mol} \mathrm{Ho})^{-1}\right)$ & $a_{\mathrm{Ho}}$
\end{tabular}

$\begin{array}{lcr}\text { In the two-phases coexisting state between HoCd and } \mathrm{HoCd}_{2} \\ 673 & 5 & 0.167 \pm 0.007 \\ 698 & 12 & 0.164 \pm 0.005 \\ 723 & 23 & 0.161 \pm 0.005 \\ 748 & 19 & 0.169 \pm 0.009 \\ 773 & 65 & 0.150 \pm 0.009 \\ 823 & 11 & 0.152 \pm 0.005\end{array}$

In the two-phases coexisting state between $\mathrm{HoCd}_{2}$ and $\mathrm{HoCd}_{3}$

$\begin{array}{lll}673 & 10 & 0.240 \pm 0.014 \\ 698 & 11 & 0.222 \pm 0.006 \\ 723 & 48 & 0.216 \pm 0.008 \\ 748 & 45 & 0.228 \pm 0.009 \\ 773 & 65 & 0.212 \pm 0.009 \\ 823 & 23 & 0.227 \pm 0.009\end{array}$

In the two-phases coexisting state between $\mathrm{HoCd}_{3}$ and $\mathrm{Ho}_{11} \mathrm{Cd}_{45}$

$\begin{array}{lll}673 & 11 & 0.307 \pm 0.004 \\ 698 & 13 & 0.309 \pm 0.005 \\ 723 & 50 & 0.301 \pm 0.009 \\ 748 & 38 & 0.312 \pm 0.009 \\ 773 & 71 & 0.298 \pm 0.013 \\ 823 & 18 & 0.300 \pm 0.009\end{array}$

In the two-phases coexisting state between $\mathrm{Ho}_{11} \mathrm{Cd}_{45}$ and $\mathrm{HoCd}_{6}$

$\begin{array}{lll}673 & 12 & 0.376 \pm 0.004 \\ 698 & 15 & 0.361 \pm 0.011 \\ 723 & 52 & 0.356 \pm 0.006 \\ 748 & 33 & 0.359 \pm 0.008 \\ 773 & 82 & 0.346 \pm 0.009 \\ 823 & 22 & 0.351 \pm 0.010\end{array}$

In the two-phases coexisting state between $\mathrm{HoCd}_{6}$ and $\mathrm{Cd}$

$\begin{array}{rrr}673 & 7 & 0.463 \pm 0.006 \\ 698 & 11 & 0.436 \pm 0.009 \\ 723 & 25 & 0.441 \pm 0.010 \\ 748 & 23 & 0.448 \pm 0.013 \\ 773 & 29 & 0.429 \pm 0.018 \\ 823 & 3 & 0.438 \pm 0.002\end{array}$

$-48.4 \pm 2.1$
$-47.4 \pm 1.4$
$-46.6 \pm 1.6$
$-49.1 \pm 2.7$
$-43.5 \pm 2.6$
$-44.0 \pm 1.4$

$(1.9 \pm 0.7) \times 10^{-4}$ $(3.0 \pm 0.7) \times 10^{-4}$ $(4.5 \pm 1.2) \times 10^{-4}$ $(4.2 \pm 2.1) \times 10^{-4}$ $(1.2 \pm 0.5) \times 10^{-3}$ $(1.7 \pm 0.3) \times 10^{-3}$

$-69.5 \pm 4.1$

$-64.1 \pm 1.6$

$-62.4 \pm 2.3$

$-66.0 \pm 2.5$

$-61.3 \pm 2.6$

$-65.7 \pm 2.6$

$-88.9 \pm 1.1$

$-89.5 \pm 1.5$

$-87.1 \pm 2.5$

$-90.2 \pm 2.6$

$-86.3 \pm 3.7$

$-86.9 \pm 2.6$

$-108.8 \pm 1.3$

$-104.4 \pm 3.2$

$-102.9 \pm 1.8$

$-104.0 \pm 2.4$

$-100.0 \pm 2.5$

$-101.6 \pm 3.0$
$(5.2 \pm 4.3) \times 10^{-6}$ $(1.7 \pm 0.5) \times 10^{-5}$ $(3.3 \pm 1.3) \times 10^{-5}$ $(2.7 \pm 1.0) \times 10^{-5}$ $(7.8 \pm 3.0) \times 10^{-5}$ $(7.3 \pm 3.1) \times 10^{-5}$

$(1.3 \pm 0.3) \times 10^{-7}$ $(2.1 \pm 0.5) \times 10^{-7}$ $(5.6 \pm 2.3) \times 10^{-7}$ $(5.5 \pm 2.0) \times 10^{-7}$ $(1.7 \pm 0.9) \times 10^{-6}$ $(3.3 \pm 1.3) \times 10^{-6}$

$(3.8 \pm 1.0) \times 10^{-9}$ $(1.7 \pm 0.7) \times 10^{-8}$ $(3.9 \pm 1.1) \times 10^{-8}$ $(6.0 \pm 2.9) \times 10^{-8}$ $(1.9 \pm 0.7) \times 10^{-7}$ $(3.9 \pm 1.8) \times 10^{-7}$

$-134.0 \pm 1.7$

$-126.2 \pm 2.5$

$-127.7 \pm 2.9$

$-129.6 \pm 3.7$

$-124.1 \pm 5.2$

$-126.7 \pm 0.6$
$(4.2 \pm 1.4) \times 10^{-11}$ $(3.9 \pm 1.1) \times 10^{-10}$ $(6.9 \pm 3.6) \times 10^{-10}$ $(1.0 \pm 0.5) \times 10^{-9}$ $(5.5 \pm 3.9) \times 10^{-9}$ $(9.2 \pm 0.8) \times 10^{-9}$ 
peaks due to Ho and $\mathrm{Cd}$, five dissolution peaks labelled $\mathrm{P}_{\mathrm{V}}^{\mathrm{a}}, \mathrm{P}_{\mathrm{IV}}^{\mathrm{a}}, \mathrm{P}_{\mathrm{III}}^{\mathrm{a}}, \mathrm{P}_{\mathrm{II}}^{\mathrm{a}}$ and $\mathrm{P}_{\mathrm{I}}^{\mathrm{a}}$, in agreement with the anodic peaks obtained by cyclic voltammetry.

Open-circuit chronopotentiometry has proven to be a convenient technique for the study of potential alloy formation in both qualitative and quantitative mode. ${ }^{12-17,27-29}$ In the present study, the measurements were conducted in the following manner, once the CdFE was electrogenerated, the intermetallic compounds were electroformed by applying more cathodic potentials. Then, the open circuit potential was measured disconnecting the potentiostatic control. During this process, a potential plateau is observed when the electrode is composed of a mixture of alloys of definite composition (i.e. a two phase coexisting state).

The equilibrium potentials were converted to electromotive forces (emf) against $\mathrm{Ho}(0)$, making them possible to estimate the relative molar Gibbs energies of Ho in the intermetallics and their Gibbs energies of formation following the methodology previously developed..$^{12,14,27,29}$ Fig. 6 displays examples of the open circuit potential transient curves at $723 \mathrm{~K}$, being possible to observe five potential plateaux labelled: I, II, III, IV and V, in agreement with the formation of five intermetallic compounds, and ratifying the results obtained by ASV and cyclic voltammetry.

Accordingly, the plateaux can be attributed to the following reactions:
Plateau I:

$$
6 \mathrm{Cd}+\mathrm{Ho}(\mathrm{III})+3 \mathrm{e} \rightarrow \mathrm{HoCd}_{6}
$$

Plateau II:

$$
\frac{45}{21} \mathrm{HoCd}_{6}+\mathrm{Ho}(\text { III })+3 \mathrm{e}^{-} \rightarrow \frac{66}{21} \mathrm{HoCd}_{45 / 11}
$$

Plateau III:

$$
\frac{33}{12} \mathrm{HoCd}_{45 / 11}+\mathrm{Ho}(\mathrm{III})+3 \mathrm{e}^{-} \rightarrow \frac{45}{12} \mathrm{HoCd}_{3}
$$

Plateau IV:

$$
2 \mathrm{HoCd}_{3}+\mathrm{Ho}(\mathrm{III})+3 \mathrm{e}^{-} \rightarrow 3 \mathrm{HoCd}_{2}
$$

Plateau V:

$$
\mathrm{HoCd}_{2}+\mathrm{Ho}(\mathrm{III})+3 \mathrm{e}^{-} \rightarrow 2 \mathrm{HoCd}
$$

In order to confirm the reproducibility of the experiment,

\begin{tabular}{|c|c|c|c|}
\hline Formation reaction & Equation for $\Delta G_{\mathrm{f}}^{0}$ & $T(\mathrm{~K})$ & $\Delta G_{\mathrm{f}}^{0}\left(\mathrm{~kJ} \mathrm{~mol}^{-1}\right)$ \\
\hline \multirow[t]{5}{*}{$\mathrm{Ho}+6 \mathrm{Cd} \rightarrow \mathrm{HoCd}_{6}$} & \multirow[t]{5}{*}{$-3 F \Delta E_{\mathrm{I}}^{*}$} & 673 & $-134.0 \pm 1.7$ \\
\hline & & 698 & $-126.2 \pm 2.5$ \\
\hline & & 748 & $-129.6 \pm 3.7$ \\
\hline & & 773 & $-124.1 \pm 5.2$ \\
\hline & & 823 & $-126.7 \pm 0.6$ \\
\hline & \multirow{4}{*}{$\frac{21}{66}\left(\frac{45}{21} \Delta G_{\mathrm{f} \operatorname{HoCd}_{6}}^{\circ}-3 F \Delta E_{\mathrm{II}}\right)$} & 723 & $-119.8 \pm 0.6$ \\
\hline & & 748 & $-121.4 \pm 0.8$ \\
\hline & & 773 & $-116.4 \pm 0.8$ \\
\hline & & 823 & $-118.7 \pm 0.9$ \\
\hline \multirow{2}{*}{$\mathrm{Ho}+3 \mathrm{Cd} \rightarrow \mathrm{HoCd}_{3}$} & \multirow{2}{*}{$\frac{12}{45}\left(\frac{33}{12} \Delta G_{\mathrm{f} \operatorname{HoCd}_{\frac{45}{11}}^{\circ}}^{\circ}-3 F \Delta E_{\mathrm{III}}\right)$} & 673 & $-116.1 \pm 0.3$ \\
\hline & & 698 & $-111.3 \pm 0.4$ \\
\hline \multirow{6}{*}{$\mathrm{Ho}+2 \mathrm{Cd} \rightarrow \mathrm{HoCd}_{2}$} & \multirow{6}{*}{$\frac{1}{3}\left(2 \Delta G_{\mathrm{f} \mathrm{HoCd}_{3}}^{\circ}-3 F \Delta E_{\mathrm{IV}}\right)$} & 673 & $-100.6 \pm 1.4$ \\
\hline & & 698 & $-95.6 \pm 0.5$ \\
\hline & & 723 & $-94.9 \pm 0.8$ \\
\hline & & 748 & $-97.4 \pm 0.8$ \\
\hline & & 773 & $-92.7 \pm 0.9$ \\
\hline & & 823 & $-95.4 \pm 0.9$ \\
\hline \multirow[t]{6}{*}{$\mathrm{Ho}+\mathrm{Cd} \rightarrow \mathrm{HoCd}$} & \multirow{6}{*}{$\frac{1}{2}\left(\Delta G_{\mathrm{f} \mathrm{HoCd}_{2}}^{\circ}-3 F \Delta E_{\mathrm{V}}\right)$} & 673 & $-74.5 \pm 1.1$ \\
\hline & & 698 & $-71.5 \pm 0.7$ \\
\hline & & 723 & $-70.7 \pm 0.8$ \\
\hline & & 748 & $-73.2 \pm 1.3$ \\
\hline & & 773 & $-68.1 \pm 1.3$ \\
\hline & & 823 & $-69.7 \pm 0.7$ \\
\hline
\end{tabular}
the measurements were repeated several times. The uncertainty was given by standard deviation for each measurement.

Table 2 Standard Gibbs free energies of Ho-Cd intermetallic compounds at various temperatures 


\section{Thermodynamic properties of Ho-Cd intermetallic} compounds

If a mixture of intermetallic compounds (e.g. $\mathrm{Ho}_{x_{1}} \mathrm{Cd}$ and $\mathrm{Ho}_{x_{2}} \mathrm{Cd}$ ) constitutes the electrode surface, the activity of Ho is fixed by the equilibrium:

$$
\mathrm{Ho}_{x_{1}} \mathrm{Cd}+\left(x_{2}-x_{1}\right) \mathrm{Ho} \rightleftharpoons \mathrm{Ho}_{x_{2}} \mathrm{Cd}
$$

and a constant value of the emf is observed along the complete transformation of the definite $\mathrm{Ho}_{x_{1}} \mathrm{Cd}$ into the definite $\mathrm{Ho}_{x_{2}} \mathrm{Cd}$.

However, if the electrode surface acquires the exact composition of an intermetallic, $\mathrm{Ho}_{x_{2}} \mathrm{Cd}$ for example, then the emf varies, from the value of the plateau corresponding to the mixture of $\mathrm{Ho}_{x_{1}} \mathrm{Cd}$ and $\mathrm{Ho}_{x_{2}} \mathrm{Cd}$ to the value of the plateau of $\mathrm{Ho}_{x_{2}} \mathrm{Cd}$ and $\mathrm{Ho}_{x_{3}} \mathrm{Cd}$ mixture.

The relative partial molar Gibbs free energies, and activities of Ho, $\Delta \tilde{G}_{\mathrm{Ho}}$ and $a_{\mathrm{Ho}}$, in the Ho-Cd intermetallic compounds, where calculated from the obtained emf, $\Delta E v s$. (Ho(III)/Ho) $/ \mathrm{V}$, through eqn (13) and (14):

$$
\begin{aligned}
& \Delta \tilde{G}_{\mathrm{Ho}}=-3 F E \\
& a_{\mathrm{Ho}}=\exp \left(\frac{-3 F E}{R T}\right)
\end{aligned}
$$

The estimated thermodynamic data are summarized in Table 1.

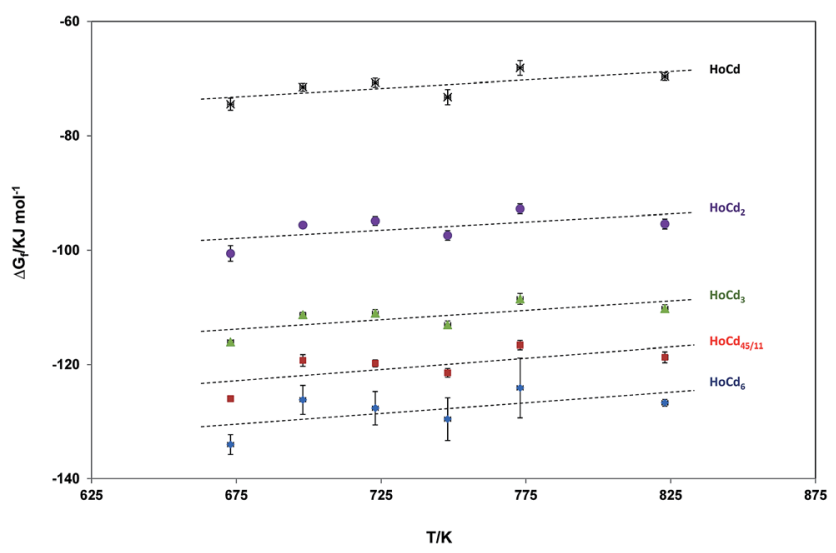

Fig. 7 Variation of the $\Delta G_{f}^{0}$ of the different $\mathrm{HoCd}_{x}$ intermetallic compounds: (*) $\mathrm{HoCd},(0) \mathrm{HoCd}_{2},(\Delta) \mathrm{HoCd}_{3},(\square) \mathrm{HoCd}_{45 / 11},(\diamond)$ $\mathrm{HoCd}_{6}$.
On the other hand, the standard Gibbs energies of formation $\Delta G_{\mathrm{f}}^{0}$ of an alloy of composition $\mathrm{Ho}_{x_{2}} \mathrm{Cd}$ is related to that of a $\mathrm{Ho}_{x_{1}} \mathrm{Cd}$ alloy by the relation:

$$
\Delta G_{\mathrm{f}}^{0}\left(\mathrm{Ho}_{x_{2}} \mathrm{Cd}\right)=-3 F \int_{x_{1}}^{x_{2}} \Delta E(x) \mathrm{d} x+\Delta G_{\mathrm{f}}^{0}\left(\mathrm{Ho}_{x_{1}} \mathrm{Cd}\right)
$$

being $x_{1}$ and $x_{2}$ the stoichiometric coefficients of Ho (i.e. $x_{1}, x_{2}=$ $1,1 / 2,1 / 3,11 / 45$ and $1 / 6$, with $x_{1}>x_{2}$ ).

The final derived equations for $\Delta G_{\mathrm{f}}^{0}$, and the obtained values at different temperatures are collected in Table 2 and Fig. 7. Moreover, the overall formation constants $\beta_{i}$ of the different intermetallic compounds have been summarized in Table 3 .

The previous data can also be used to calculate the relative partial molar Gibbs free energies of Cd, $\Delta \tilde{G}_{\mathrm{Cd}}$, and activities of $\mathrm{Cd}$ in the intermetallic compounds taken into account the reaction:

$$
\mathrm{Ho}+x \mathrm{Cd} \rightarrow \mathrm{HoCd}_{x}
$$

by means of the following equations ${ }^{30}$

$$
\begin{gathered}
\Delta G_{\mathrm{f}}^{0}\left(\mathrm{HoCd}_{x}\right)=\Delta \tilde{G}_{\mathrm{Ho}}+x \Delta \tilde{G}_{\mathrm{Cd}} \\
\tilde{G}_{\mathrm{Cd}}=R T \ln a_{\mathrm{Cd}}
\end{gathered}
$$

The obtained values are collected in Table 4 .

\section{Evaluation of Cd distillation at high temperature}

Following the methodology proposed by Shibata et al. ${ }^{16}$ and Kurata et al., ${ }^{31}$ based on the Scientific Group Thermodata Europe (SGTE) database, ${ }^{32}$ the Gibbs free energy of Ho-Cd intermetallic compounds, $\mathrm{G}\left(\mathrm{HoCd}_{x}\right)$, can be indicated with respect to the enthalpies of the pure elements in their reference states at $298.15 \mathrm{~K}$, by the following equation:

$$
\frac{\Delta G_{\mathrm{f}}^{0}\left(\mathrm{HoCd}_{x}\right)}{x+1}=\frac{G\left(\mathrm{HoCd}_{x}\right)}{x+1}-\frac{1}{x+1} H_{\mathrm{Ho}}^{\mathrm{hcp}, 298 \mathrm{~K}}-\frac{x}{x+1} H_{\mathrm{Cd}}^{\mathrm{liq}, 298 \mathrm{~K}}
$$

where $H_{\mathrm{Ho}}^{\mathrm{hcp}, 298.15 \mathrm{~K}}$ and $H_{\mathrm{Cd}}^{\mathrm{liq}, 298.15 \mathrm{~K}}$ are the enthalpies at 298.15 $\mathrm{K}$ in their reference states, -7.996 and $-6.247 \mathrm{~kJ} \mathrm{~mol}^{-1}$,

\begin{tabular}{|c|c|c|c|}
\hline $\begin{array}{l}\text { Intermetallic } \\
\text { compound }\end{array}$ & $\begin{array}{l}\text { Number of } \\
\text { data }\end{array}$ & Formation reaction & $\beta_{i}$ \\
\hline $\mathrm{HoCd}_{6}$ & 98 & $\mathrm{Ho}+6 \mathrm{Cd} \rightarrow \mathrm{HoCd}_{6}$ & $\beta_{6}=\exp (-6.80+20329 / T)$ \\
\hline $\operatorname{HoCd}_{45 / 11}$ & 216 & $\mathrm{Ho}+\frac{45}{11} \mathrm{CdHoCd}_{\frac{45}{11}}$ & $\beta_{45 / 11}=\exp (-5.54+18459 / T)$ \\
\hline $\mathrm{HoCd}_{3}$ & 201 & $\mathrm{Ho}+3 \mathrm{Cd} \rightarrow \mathrm{HoCd}_{3}$ & $\beta_{3}=\exp (-4.73+16857 / T)$ \\
\hline $\mathrm{HoCd}_{2}$ & 197 & $\mathrm{Ho}+2 \mathrm{Cd} \rightarrow \mathrm{HoCd}_{2}$ & $\beta_{2}=\exp (-3.65+14181 / T)$ \\
\hline HoCd & 135 & $\mathrm{Ho}+\mathrm{Cd} \rightarrow \mathrm{HoCd}$ & $\beta_{1}=\exp (-4.64+11911 / T)$ \\
\hline
\end{tabular}
respectively. ${ }^{31}$

Fig. 8 shows the obtained Gibbs free energy of Ho-Cd intermetallic compounds as a function of atomic fraction of Ho.

Although the decomposition temperature of $\mathrm{HoCd}_{6}$ is not known, its Gibbs free energy has been represented assuming that $\mathrm{HoCd}_{6}$ is not decomposed below $1000 \mathrm{~K}$. Gibbs free energy

Table 3 -Overall formation constants $\beta_{i}$ of the different intermetallic 
Table 4 Thermodynamic properties of $\mathrm{Cd}$ for Ho-Cd intermetallic compounds in two-phase coexisting states at various temperatures

\begin{tabular}{lll}
\hline$T / \mathrm{K}$ & $\Delta \tilde{G}_{\mathrm{Cd}}\left(\mathrm{kJ}(\mathrm{mol} \mathrm{Ho})^{-1}\right.$ & $a_{\mathrm{cd}}$ \\
\hline
\end{tabular}

In the two-phases coexisting state between $\mathrm{HoCd}$ and $\mathrm{HoCd}_{2}$

$\begin{array}{lll}673 & -26.1 \pm 1.1 & (9.5 \pm 1.8) \times 10^{-3} \\ 698 & -24.1 \pm 0.7 & (1.6 \pm 0.2) \times 10^{-2} \\ 723 & -24.1 \pm 0.8 & (1.8 \pm 0.2) \times 10^{-2} \\ 748 & -24.2 \pm 1.3 & (2.1 \pm 0.4) \times 10^{-2} \\ 773 & -24.6 \pm 1.3 & (2.2 \pm 0.4) \times 10^{-2} \\ 823 & -25.7 \pm 0.7 & (2.3 \pm 0.2) \times 10^{-2}\end{array}$

In the two-phases coexisting state between $\mathrm{HoCd}_{2}$ and $\mathrm{HoCd}_{3}$

$\begin{array}{lll}673 & -15.5 \pm 1.4 & (6.4 \pm 1.5) \times 10^{-2} \\ 698 & -15.7 \pm 0.5 & (6.7 \pm 0.6) \times 10^{-2} \\ 723 & -16.2 \pm 0.8 & (6.8 \pm 0.9) \times 10^{-2} \\ 748 & -15.7 \pm 0.8 & (8.1 \pm 1.1) \times 10^{-2} \\ 773 & -15.7 \pm 0.9 & (8.8 \pm 1.0) \times 10^{-2} \\ 823 & -14.8 \pm 0.9 & (1.2 \pm 0.1) \times 10^{-1}\end{array}$

In the two-phases coexisting state between $\mathrm{HoCd}_{3}$ and $\mathrm{Ho}_{11} \mathrm{Cd}_{45}$

$\begin{array}{lll}673 & -9.1 \pm 0.3 & (2.0 \pm 0.1) \times 10^{-1} \\ 698 & -7.3 \pm 0.4 & (2.9 \pm 0.2) \times 10^{-1} \\ 723 & -8.0 \pm 0.6 & (2.7 \pm 0.3) \times 10^{-1} \\ 748 & -7.6 \pm 0.6 & (2.9 \pm 0.3) \times 10^{-1} \\ 773 & -7.4 \pm 0.9 & (3.2 \pm 0.4) \times 10^{-1} \\ 823 & -7.8 \pm 0.6 & (3.2 \pm 0.3) \times 10^{-1}\end{array}$

In the two-phases coexisting state between $\mathrm{Ho}_{11} \mathrm{Cd}_{45}$ and $\mathrm{HoCd}_{6}$

$\begin{array}{lll}673 & -4.2 \pm 0.2 & (4.7 \pm 0.2) \times 10^{-1} \\ 698 & -3.6 \pm 0.5 & (5.4 \pm 0.5) \times 10^{-1} \\ 723 & -4.1 \pm 0.3 & (5.0 \pm 0.3) \times 10^{-1} \\ 748 & -4.3 \pm 0.4 & (5.1 \pm 0.3) \times 10^{-1} \\ 773 & -4.1 \pm 0.4 & (5.4 \pm 0.4) \times 10^{-1} \\ 823 & -4.2 \pm 0.5 & (5.4 \pm 0.4) \times 10^{-1}\end{array}$

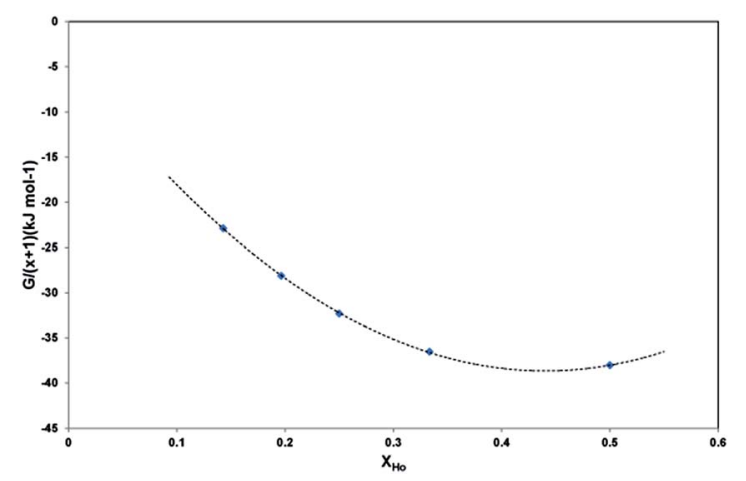

Fig. 8 Gibbs free energies of $\mathrm{Ho}-\mathrm{Cd}$ intermetallics compounds at $973 \mathrm{~K}$.

of Ho-Cd intermetallic compounds decreases gradually from $\mathrm{HoCd}_{6}$ to HoCd and attains the minimum value at $\mathrm{HoCd}_{2}$ and HoCd, suggesting that both intermetallics are relatively stable. Therefore, considering cathode product obtained by electrorefining of $\mathrm{U}-\mathrm{Pu}-\mathrm{Zr}$ metal fuel, significant amounts of $\mathrm{U}$ and $\mathrm{Pu}$ might be contained in the stables $\mathrm{HoCd}_{2}$ and/or HoCd, which might affect their decomposition, a similar result to those reported by Shibata et al. ${ }^{16}$ in the stable $\mathrm{CeCd}_{2}$.

\section{Conclusions}

It has been proved that the electro-reduction of Ho(III) at liquid $\mathrm{Cd}$ electrodes (i.e. Cd pool and Cd coated tungsten electrode) can be conveniently elucidated by electrochemical techniques. Due to a lowering of the activity of Ho in the metal phase, the redox potential of the $\mathrm{Ho}(\mathrm{III}) / \mathrm{Ho}$ couple at both electrodes was observed at more positive potential values than at inert ones.

$\mathrm{CV}$, ASV, and OCP measurements using a Cd coated tungsten electrode have proven to be particularly useful for phase identification in intermetallic compounds. For avoiding the semiinfinite diffusion model, a CdFE has been chosen instead of a Cd pool, making possible the formation of distinct nonhomogeneous phases during deposition.

Electromotive force, emf, measurements for various intermetallic compounds in two-phase coexisting states were carried out in the temperature range of 673-823 K. The activities and relative partial molar Gibbs energies of Ho were obtained from the measured emf for $\operatorname{HoCd}_{6}, \operatorname{HoCd}_{45 / 11}, \operatorname{HoCd}_{3}, \operatorname{HoCd}_{2}$ and HoCd intermetallic compounds. The formation energy of each intermetallic compound, and the global formation constants were also calculated. Moreover, the activities and relative partial molar Gibbs energies of Cd have also been calculated.

By extrapolating the molar Gibbs free energy of Ho-Cd intermetallic compounds to the $\mathrm{Cd}$ distillation temperature, it was observed that the molar Gibbs free energy of Ho in Ho-Cd intermetallic compounds decreases gradually from $\mathrm{HoCd}_{6}$ to HoCd and attains to the minimum value at $\mathrm{HoCd}_{2}$ and $\mathrm{HoCd}$. This suggests on the Cd distillation from the $\mathrm{U}-\mathrm{Pu}-\mathrm{Ho}-\mathrm{Cd}$ alloy that the dissolution of $\mathrm{U}$ or $\mathrm{Pu}$ into $\mathrm{HoCd}_{2}$ and $\mathrm{HoCd}$ should be mostly taken into consideration.

\section{Acknowledgements}

Authors thank the Junta de Castilla y León (Spain), Project VA171U14 for financial support.

\section{Notes and references}

1 P. Carbol, D. Serrano-Purroy, E. Gonzalez-Robles, E. Hrnecek, F. Quinto, P. Soucek, R. Malmbeck, S. van Winckel and J.-P. Glatz, Procedia Chem., 2012, 7, 202-208.

2 J. P. Glatz, R. Malmbeck, P. Soucek, B. Claux, R. Mejer, M. Ougier and Y. Murakami, Molten Salt Chemistry from lab to applications, Elsevier, 2013, ch. 26, p. 541.

3 T. Wakabayashi, Prog. Nucl. Energy, 2002, 40, 457-463.

4 P. Chamelot, L. Massot, M. Gibilaro and P. Taxil, Molten Salt Chemistry from lab to applications, Elsevier, 2013, ch. 25, p. 521.

5 O. Shirai, M. Iizuka, T. Iwai, Y. Suzuki and Y. Arai, J. Electroanal. Chem., 2000, 490, 31-36.

6 K. Uozumi, M. Iizuka, T. Kato, T. Inoue, O. Shirai, T. Iwai and Y. Arai, J. Nucl. Mater., 2004, 325, 34-43.

7 G. Kim, D. Yoon, S. Paek, S. Kim, T. Kim and D. Ahn, J. Electroanal. Chem., 2012, 682, 128-135.

8 O. Shirai, K. Uozumi, T. Iwai and Y. Arai, J. Appl. Electrochem., 2004, 34, 323-330. 
9 H. Hayashi, M. Akabori and K. Minato, Nucl. Technol., 2008, 162, 129-134.

10 T. Murakami, Y. Sakamura, N. Akiyama, S. Kitawaki, A. Nakayoshi and T. Koyama, Procedia Chem., 2012, 7, 798803.

11 T. Murakami and T. Koyama, J. Electrochem. Soc., 2011, 158, F147-F153.

12 Y. Castrillejo, M. R. Bermejo, P. Díaz Arocas, A. M. Martínez and E. Barrado, J. Electroanal. Chem., 2005, 579, 343-358.

13 O. Shirai, A. Uehara, T. Fujii and H. Yamana, J. Nucl. Mater., 2005, 344, 142-145.

14 Y. Castrillejo, R. Bermejo, A. M. Martínez, E. Barrado and P. Díaz Arocas, J. Nucl. Mater., 2007, 360, 32-42.

15 S. Kim, S. Paek, T. Kim, D. Park and D. Ahn, Electrochim. Acta, 2012, 85, 332-335.

16 H. Shibata, H. Hayashi, M. Akabori, Y. Arai and M. Kurata, J. Phys. Chem. Solids, 2014, 75, 972-976.

17 Y. Castrillejo, P. Hernández, R. Fernández and E. Barrado, Electrochim. Acta, 2014, 147, 743-751.

18 S. Ghosh, R. Ganesan, R. Sridharan and T. Gnanasekaran, J. Nucl. Mater., 2015, 467, 280-285.

19 D. Yoon, S. Phongikaroon and J. Zhang, J. Electrochem. Soc., 2016, 163(3), E97-E103.

20 Y. Castrillejo, M. R. Bermejo, E. Barrado, J. Medina and A. M. Martínez, J. Electrochem. Soc., 2006, 153(10), C713C721.
21 K. A. Gschneidner Jr and F. W. Calderwood, Bull. Alloy Phase Diagrams, 1988, 9(1), 31-32.

$22 \mathrm{M}$. Noel and K. I. Vasu, Cyclic voltammetry and the frontiers of electrochemistry, Oxford \& IBH Publishing Co. Pvt. Ltd, New Delhi, 1990.

23 G. de Córdoba, A. Laplace, O. Conocar, J. Lacquement and C. Caravaca, Electrochim. Acta, 2008, 54, 280-288.

24 G. de Córdoba, A. Laplace, O. Conocar and J. Lacquement, J. Nucl. Mater., 2009, 393, 459-464.

25 M. Jafarian and J. Bouteillon, Electrochim. Acta, 1990, 35, 1201-1208.

26 V. D. Jovick, A. R. Despic, J. S. Stevanovic and S. Spaic, Electrochim. Acta, 1989, 34, 1093-1102.

27 I. H. Konishi, T. Nishikiori, T. Nohira and Y. Ito, Electrochim. Acta, 2003, 48, 1403-1408.

28 Y. Castrillejo, A. Vega, M. Vega, P. Hernández, J. A. Rodriguez and E. Barrado, Electrochim. Acta, 2014, 118, 58-66.

29 G. S. Picard, Y. E. Mottot and B. L. Tremillon, J. Electrochem. Soc., 1984, 84, 585-602.

30 C. Wagner, Thermodynamics of alloys, Addison-Wesley Press, Inc, Cambridge, USA, 1952.

31 M. Kurata and Y. Sakamura, J. Phase Equilib., 2001, 22(3), 232-240.

32 A. T. Dinsdale, Calphad, 1991, 15, 317-425. 